\title{
Slow or swift, your patients' experience won't drift: absence of correlation between physician productivity and the patient experience
}

\author{
Kasia Lenz, MD*; Andrew McRae, MD, PhD*; Dongmei Wang, MSc*; Benjamin Higgins, $\mathrm{MA}^{\dagger}$; \\ Grant Innes, MD*; Timothy Cook, $\mathrm{BSc}^{\dagger}$; Eddy Lang, MD*
}

\section{ABSRACT}

Objectives: To evaluate the relationship between Emergency Physician (EP) productivity and patient satisfaction with Emergency Department (ED) care.

Methods: This retrospective observational study linked administrative and patient experience databases to measure correlations between the patient experience and EP productivity. The study was performed across three Calgary EDs (from June 2010 to July 2013). Patients $>16$ years old with completed Health Quality Council of Alberta (HQCA) ED Patient Experience Surveys were included. EP productivity was measured at the individual physician level and defined as the average number of patients seen per hour. The association between physician productivity and patient experience scores from six composite domains of the HQCA ED Patient Experience Survey were examined using Pearson correlation coefficients, linear regression modelling, and a path analysis.

Results: We correlated 3,794 patient experience surveys with productivity data for 130 EPs. Very weak non-significant negative correlations existed between productivity and survey composites: "Staff Care and Communication" $(r=$ -0.057, $p=0.521)$, “Discharge Communication" ( $r=-0.144$, $p=0.102)$, and "Respect" ( $r=-0.027, p=0.760)$. Very weak, non-significant positive correlations existed between productivity and the composite domains: "Medication Communication" ( $r=0.003, p=0.974)$ and "Pain management" $(r=0.020$, $p=0.824)$. A univariate general linear model yielded no statistically significant correlations between EP productivity and patient experience, and the path analysis failed to show a relationship between the variables.

Conclusion: We found no correlation between EP productivity and the patient experience.

\section{RÉSUMÉ}

Objectif: L'étude visait à évaluer la relation entre la rapidité des médecins d'urgence (MU) et le degré de satisfaction des patients au regard des soins reçus au service des urgences (SU).
Méthode: Il s'agit d'une étude rétrospective d'observation dans laquelle des données administratives ont été liées à des données sur l'expérience des patients afin de mesurer le degré de corrélation entre l'expérience des patients et la productivité des MU. L'étude a été menée dans trois SU, à Calgary (juin 2010 - juillet 2013). Ont été inclus dans l'étude des patients $>16$ ans ayant rempli le questionnaire Health Quality Council of Alberta (HOCA) sur leur expérience au SU. Pour ce qui de la productivité des $\mathrm{MU}$, elle a été mesurée sur une base individuelle et elle a été définie comme le nombre moyen de patients examinés à l'heure. La relation entre la productivité des $\mathrm{MU}$ et l'expérience des patients, fondée sur les résultats obtenus dans 6 domaines composés de I'HOCA relativement à l'expérience des patients au SU a été examinée à I'aide de coefficients de corrélation de Pearson, d'un modèle de régression linéaire et d'une analyse des pistes causales.

Résultats: Au total, 3794 questionnaires sur l'expérience des patients ont été mis en corrélation avec des données sur la productivité concernant $130 \mathrm{MU}$. Se sont dégagées des analyses, des corrélations négatives, très faibles, non significatives entre la productivité et les domaines composés liés aux communications et aux soins donnés par le personnel ( $r=-0,057 ; p=0,521)$, aux communications au moment $d u$ congé $(r=-0,144 ; p=0,102)$ et au respect $(r=-0,027$; $p=0,760)$. Se sont aussi dégagées des analyses, des corrélations positives, très faibles, non significatives entre la productivité et les domaines composés liés aux communications relatives aux médicaments $(r=0,003 ; p=0,974)$ et à la prise en charge de la douleur $(r=0,020 ; p=0,824)$. D'ailleurs, un modèle de régression linéaire général et unidimensionnel a fait ressortir l'absence de corrélation statistiquement significative entre la productivité des MU et l'expérience des patients, et il en est allé de même pour l'analyse des pistes causales au regard des relations entre les différentes variables.

Conclusion: L'étude n'a pas permis d'établir de relation entre la productivité des MU et l'expérience des patients.

Keywords: Patient experience, productivity, Emergency Physician, patient satisfaction, efficiency

From the *Department of Emergency Medicine, University of Calgary, Calgary, AB; and tHealth Quality Council of Alberta, Calgary, AB.

Correspondence to: Dr. Kasia Lenz, Department of Emergency Medicine, Foothills Medical Centre, Room C231, 1403 - 29 St. NW, Calgary, AB. T2N 2T9; Email: kasia.lenz@albertahealthservices.ca. 


\section{INTRODUCTION}

Emergency Departments (EDs) are complex, fast paced environments set up to quickly and efficiently diagnose and address patient complaints. For many years, EDs have been struggling with crowding and access block; recently this problem has become particularly dire. ${ }^{1-6}$ Increased physician productivity (patients seen per hour), may enhance ED operational efficiency if associated with reduced patient wait times, and is financially rewarding to physicians working within volume-incentivised compensation models such as fee-for-service. ${ }^{7}$ However, rapid care may limit the duration and quality of physician-patient interactions, which are primary determinants of the patient experience. ${ }^{8,9}$ One way of measuring how patients are affected by the constraints placed on physicians and EDs is to measure the quality of the patient experience during their ED visit. In fact, some argue that the quality of health care in EDs is best reflected in patient experience measures. ${ }^{5,10,11}$

One challenge in measuring the patient experience is that it is composed of many contributing factors with variable strengths of influence. ${ }^{12}$ Factors such as resource availability, patient age and health status, perceived and expected wait times, and illness acuity ${ }^{5,10,13-15}$ all influence patient satisfaction. However, the strongest predictor of patient satisfaction appears to be the quality of interpersonal interaction with care providers. ${ }^{12,16}$ Furthermore, a USA study found that patient dissatisfaction relates more to the ability of a physician to meet patient expectations and communicate effectively than it does to the medical complexity of a patient's case. ${ }^{17}$

Numerous studies have evaluated these determinants of ED patient experience; however, there are limited data quantifying the relationship between patient satisfaction, interpersonal experiences, and Emergency Physician (EP) productivity, while existing studies rarely have survey response rates greater than $20 \% .^{12,18-22}$ The relationship between physician productivity and patient perception of care is critical if the pressuring of EPs to be more efficient compromises the patient experience.

Our objective was to assess the relationship between EPs productivity and patients' satisfaction with ED care provided. We assumed that physicians who saw larger numbers of patients hourly were spending less time with each patient. Thus we considered productivity to be inversely related to the quality of interpersonal interaction between the physician and the patient and hence the patient experience. We hypothesised that patient satisfaction with ED care would decrease as the number of patients seen per hour by the physician increased.

\section{METHODS}

This retrospective observational study, performed in collaboration with the Health Quality Council of Alberta (HQCA), linked Calgary regional EPs performance data with the validated HQCA Patient Experience Surveys completed during the same time period. Linking these data allowed us to assess the correlation between EP productivity and patient satisfaction with their ED interactions.

\section{Study setting and population}

The study was performed in three urban EDs within the Calgary Health Region (Foothills Medical Centre, Rockyview General Hospital and Peter Lougheed Centre) between June 2010 and July 2013. Average ED census for each ED ranged from 75,000 to 79,000 visits per year; approximately $15 \%$ of visits involved a resident and $10 \%$ involved a medical student. The survey population included patients over 16 years old who presented to one of the three EDs and completed an HQCA ED Patient Experience Survey. All physicians were remunerated on a fee-for-service basis and were excluded from the analysis if they had less than 10 completed survey responses. The study was approved by the University of Calgary Research Ethics Board (REB13-0092).

\section{Data sources}

The HQCA, an organization independent from the provincial health authority, has a legislated mandate to measure, monitor, and assess patient safety and health care quality, and to collaborate with health authorities in making recommendations for improvement. ${ }^{16}$ Since 2007, the HQCA has been administering the HQCA ED Patient Experience Survey to patients in Alberta's 15 busiest EDs. ${ }^{16}$ This survey was developed by Picker Europe for the British National Health Service and Healthcare Commission, and was selected by the HQCA for its relevance, availability, and level of validation. $^{23,24}$ Further details about the survey tool 
selection, adaptation, validation, consent process, and application can be found in the 2007 HQCA Emergency Department Patient Experience Survey Report. ${ }^{25}$

From the HQCA surveys, we identified key items of patient experience most influenced by physicians. These individual survey questions were grouped into six composite domains as previously identified by the $\mathrm{HQCA}^{25}$ to improve the robustness of obtained responses. The domains each address a common patient experience issue and are defined as follows:

1. Staff Care: how well ED staff discussed and explained a patient's medical condition, plan, and results. How well they listened to patients' concerns. How much did patients trust their physicians and feel that they were involved in decision-making.

2. Pain Management: how effectively and efficiently pain was managed by ED staff.

3. Discharge Communication: how well staff discussed discharge plans, follow-up care, danger signs to be aware of, and how well they addressed any concerns prior to discharge.

4. Respect: how respectful were staff of patients and their families.

5. Medication Communication: how effectively medication use and side effects were explained to patients.

6. Wait Time and Crowding: how did wait time and crowding influence the patient experience.

A full list of the questions used in each composite domain can be found in Appendix 1.

Physician productivity was defined as the average number of patients seen per scheduled work hour over the sampling interval. ${ }^{26}$ Productivity information was extracted from the Real-Time Emergency Department Information System (REDIS) used in the Calgary Zone of Alberta Health Services until April 2013 and the Sunrise Emergency Care (SEC) used since May 2013 in all Calgary Zone facilities. EP productivity levels and HQCA Patient Experience Survey outcomes were then correlated for individual EPs, and de-identified data was provided to the research team for analysis. Our primary objective was to determine whether a correlation existed between ED physician productivity and ED patient experience.

\section{Statistical analysis}

A post-hoc power calculation was performed $\left(\mathrm{G}^{*}\right.$ Power 3.01.0) which confirmed that our sample size was sufficient to detect an effect as 0.0613 with a beta error of 0.80. The data was analysed using SPSS (IBM Statistics Version 19). We used descriptive statistics to analyse the composite satisfaction domains as well as average physician productivity (patients/hour). We used a Pearson correlation coefficient to examine the bivariate relationships between physician productivity and patient satisfaction domains. We then used multivariable linear regression models to further quantify the association between physician productivity and patient experience scores. After the assumptions of linear regression were assessed, we developed models with the score for each patient experience domain as the dependent variable and physician productivity as the independent variable along with physician age, training route (CCFP EM or FRCPC), average patient age per shift, and proportion of patients admitted per physician as potential confounders. A backward stepwise selection procedure was used to generate the most parsimonious model for each satisfaction variable.

Finally, we performed a path analysis using Stata Statistical Software (StataCorp. Release 12). This method is an extension of a regression model and examines whether variables influence each other in a chain-like fashion. In other words, it tests for interrelationships between variables. ${ }^{27,28}$ The path analysis was broken up into two sections. The first decomposed the effects of physician and patient characteristics on physician productivity and the second decomposed those characteristics on patient experience ratings. For a more complete explanation of the path analysis, please refer to Appendix 2.

\section{RESULTS}

During the study period, 3,794 patient surveys were completed for 130 eligible ED physicians. Overall, the survey response rate was $45 \%$. Mean patient age was 52 years $(\mathrm{SD}=20 ; 45 \%$ male). Mean physician age was 45 years $(\mathrm{SD}=9 ; 80 \%$ male) (Table 1$)$. A detailed table of physician productivity versus composite domain scores can be found in Appendix 3.

Very weak non-significant negative correlations existed between productivity and the composites: "Staff Care" $(\mathrm{r}=-0.057, \quad p=0.521), \quad$ "Discharge Communication" $(\mathrm{r}=-0.144, \quad p=0.102)$, "Respect" ( $\mathrm{r}=-0.027, p=0.760)$, and "Wait Time and Crowding" $(\mathrm{r}=-0.064, p=0.470)$. Very weak non-significant positive correlations existed between productivity and 
Absence of correlation between physician productivity and the patient experience

\begin{tabular}{|c|c|c|}
\hline Variable & \multicolumn{2}{|c|}{ Physician Characteristics } \\
\hline No. of physicians & 130 & \\
\hline No. of Male (\%) & $104(80 \%)$ & \\
\hline Mean Age (SD) & $44.85(9.26)$ & \\
\hline No. of Fee for Services (\%) & $130(100 \%)$ & \\
\hline \multirow[t]{2}{*}{ No. from FRCPC Program (\%) } & $52(40 \%)$ & \\
\hline & Mean (SD) & Median (IQR) \\
\hline Productivity (pts/hr) & $2.03(0.36)$ & $1.99(1.81-2.20)$ \\
\hline Survey Count & $29.7(14.98)$ & $26(18.75-38.00)$ \\
\hline Staff Care Composite Score & $80.84(4.66)$ & $81.10(77.35-83.95)$ \\
\hline Discharge Information Composite Score & $57.14(9.01)$ & $56.55(50.75-63.23)$ \\
\hline Medication Information Composite Score & $79.80(10.40)$ & $81.10(73.80-86.10)$ \\
\hline Respect Composite Score & $85.51(3.40)$ & $85.75(83.30-87.83)$ \\
\hline Pain Management Composite Score & $66.35(9.36)$ & $65.80(59.55-72.60)$ \\
\hline Wait Time Composite Score & $52.27(7.28)$ & $51.85(47.80-56.43)$ \\
\hline
\end{tabular}

Table 2. Pearson correlation results comparing composite domain outcomes to physician productivity.

\begin{tabular}{lcc} 
& & Significance \\
Composite Domain & Pearson Correlation & $(p)$ \\
\hline Staff Care & -0.057 & 0.521 \\
Discharge Communication & -0.144 & 0.102 \\
Respect & 0.011 & 0.899 \\
Medication Communication & -0.027 & 0.974 \\
Pain Management & 0.020 & 0.824 \\
Wait Time and Crowding & 0.064 & 0.470
\end{tabular}

composites: "Medication Communication" $(\mathrm{r}=0.003$, $p=0.974)$ and "Pain Management" $(\mathrm{r}=0.020$, $p=0.824)$ (Table 2). Scatter plots that visually represented the relationship between productivity and each patient experience domain did not suggest an alternative non-linear relationship (Figures 1-6).

Linear regression modelling did not identify any statistically significant association between physician productivity and any of the composite domains of patient satisfaction (Table 3) after adjusting for potential confounders.

Both decompositions in our path analysis reinforced the findings of the primary analysis. Standardized coefficients showed that physician training program, physician age, patient age, and admission status had weak, non-significant effects on physician productivity (see Table 4). These variables had no significant effect on patient experience either directly through physician

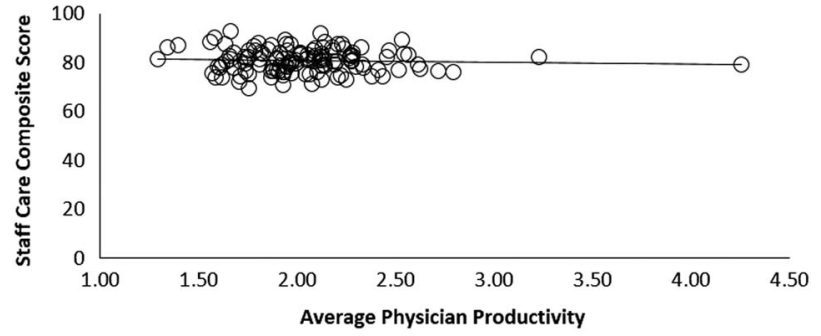

Figure 1. Patient experience score in the Staff Care Composite domain versus physician productivity

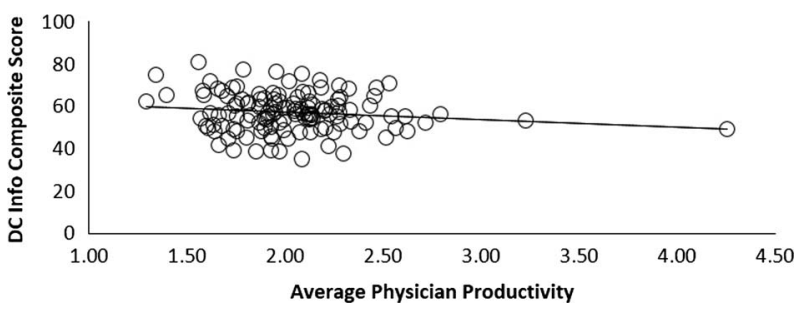

Figure 2. Patient experience score in the Discharge Information Composite domain versus physician productivity.

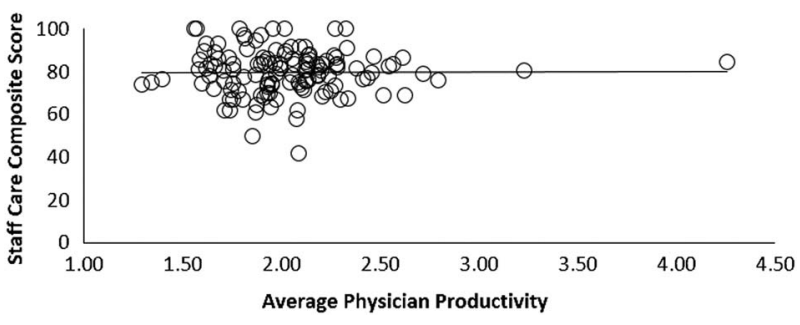

Figure 3. Patient experience score in the Medication Communication Composite domain versus physician productivity 
productivity or indirectly by modifying physician productivity. We found that the patient experience ratings regarding "Medication Communication" and "Wait Time and Crowding" improved when a higher percentage of patients were admitted (total effects: $0.188 ; p=.037$ and $0.214 ; p=0.016$, respectively) (see Table 5). ${ }^{29}$

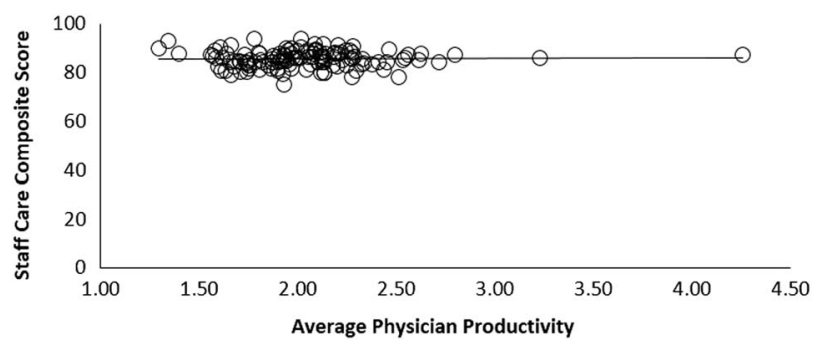

Figure 4. Patient experience score in the Respect Composite domain versus physician productivity.

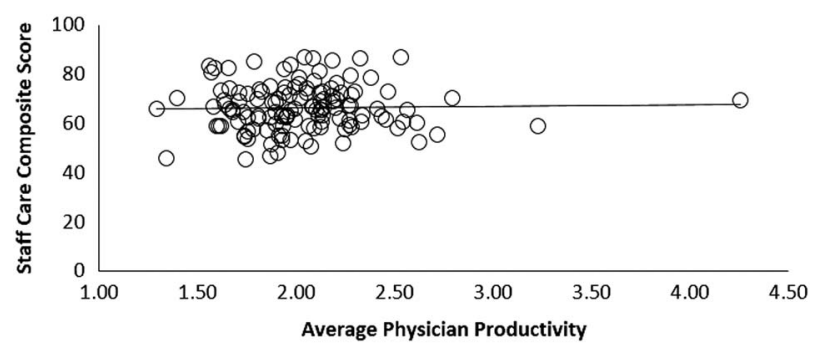

Figure 5. Patient experience score in the Pain Management Composite domain versus physician productivity.

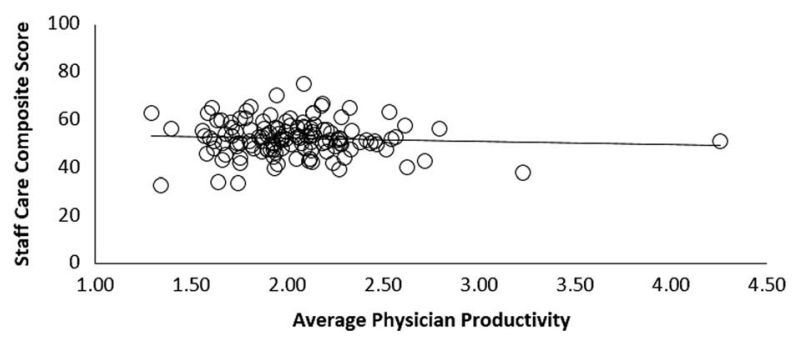

Figure 6. Patient experience score in the Wait Time and Crowding Composite domain versus physician productivity

\section{DISCUSSION}

Our findings showed no linear relationship between EP productivity and the patient experience. Visual examination of scatter plots did not suggest any alternative non-linear relationship. The only relationship that approached statistical significance was the relationship between physician productivity and satisfaction with discharge instructions. Similar non-significant associations between physician productivity and patient satisfaction have been reported in USA primary care settings. ${ }^{30}$ Nonetheless, these results were surprising given the rational link between productivity, throughput, and wait times, and the logical assumption that more "efficient" physicians have less time to devote to patient communication and rapport. One potential explanation for our finding is that patients in our study may place high value on physicians who provide care in an efficient fashion. Whereas patients in other clinical settings may be expecting lengthy discussions of their health, ED patients may be expecting fast care and are more satisfied when this expectation is met.

Because findings were discordant with our hypothesis, we performed a path analysis to determine if interrelationships between variables were confounding the observed relationship between EP productivity and patient experience. For example, patient age was associated with greater complexity, reduced EP productivity, higher admission rates, and differences in patient experience; therefore, any observed differences in patient experience could be due to factors other than the proposed explanatory variable of EP productivity. Although we found some statistically significant associations in the domains of "Medication Communication" and "Wait Time and Crowding" when a higher percentage of patients were admitted, it is important to note that the indirect effects via physician

\begin{tabular}{|lccc|}
\hline \multicolumn{4}{|l|}{ Table 3. General linear model results comparing composite domains to physician productivity } \\
\hline Composite domain & Regression coefficient (B) & $95 \% \mathrm{Cl}$ & Significance $(p)$ \\
\hline Staff Care & -0.864 & $-3.098,1.370$ & 0.445 \\
Discharge Communication & -3.425 & $-7.711,0.861$ & 0.116 \\
Respect & -0.337 & $-2.101,1.427$ & 0.706 \\
Medication Communication & -0.241 & $-5.186,4.703$ & 0.923 \\
Pain Management & 0.758 & $-3.731,5.247$ & 0.739 \\
Wait Time/Crowding & -1.664 & $-5.145,1.809$ & 0.344 \\
\hline
\end{tabular}


Absence of correlation between physician productivity and the patient experience

\begin{tabular}{|c|c|c|c|c|c|}
\hline \multirow[b]{2}{*}{ Outcome variable } & \multicolumn{2}{|c|}{ Pre-determined variable } & \multirow[b]{2}{*}{ Total effect } & \multirow[b]{2}{*}{ Indirect effects } & \multirow[b]{2}{*}{ Direct effect } \\
\hline & Variable & Element & & & \\
\hline \multirow[t]{5}{*}{ Physician productivity } & Admitted patients & Percentage of patients admitted & -0.007 & & -0.007 \\
\hline & Patients' age & Average age of physicians' patients & -0.117 & & -0.117 \\
\hline & Physician training program & Base case: CCFP-EM & & & \\
\hline & & FRCPC & -0.040 & & -0.040 \\
\hline & Physician age & Age in 2012 & 0.030 & & 0.030 \\
\hline
\end{tabular}

productivity were extremely small ( 0 for "Medication Communication" and 0.001 for "Wait Time and Crowding"). Thus, these impacts most likely reflected the higher complexity of admitted patients than any relationship to physician productivity.

Despite previous findings that interpersonal interactions between physicians and patients were the strongest predictors of patient satisfaction ${ }^{12,31}$ our study suggests that time spent with physicians does not by itself determine the perceived quality of the interaction. This implies that EPs' ability to establish positive rapport with their patients was independent of their productivity, which further contributes to an increasing body of literature suggesting that multiple factors (e.g., physician technical skill, wait times) influence patient satisfaction. ${ }^{12,30-32}$ This apparent lack of association between productivity and patient experience may simply be due to methodological differences between our study and the majority of published literature on the subject. ${ }^{12,31}$ For example, most of the existing studies were conducted in USA EDs, which represent a dramatically different environment from the publically funded Canadian EDs we examined.

This study had several strengths. Notably, it is the first to correlate EP productivity performance with patient experience in an ED population. Similar studies have been done in clinics or inpatient settings, but these may not be generalizable to the ED. ${ }^{30}$ Second, we were able to link a large sample of patient satisfaction scores with physician productivity data. Furthermore, the $45 \%$ survey response rates in this study were relatively high. Typically, ED patient satisfaction surveys yield response rates around $25 \%-30 \%$, with some studies as low as $15 \% .^{19,22,23,33}$ Finally, the data we used was collected using an internationally validated tool that was administered by an arm's length organization, thereby, reducing collection bias. ${ }^{23,24}$

\section{LIMITATIONS}

Our study adapted data that was collected for a different purpose. Although the survey tool is widely validated, its purpose was not solely to evaluate the patientphysician interaction, but rather the patient experience with all care providers in the department. Therefore, a degree of instrument bias may have been introduced ${ }^{34}$ potentially decreasing the sensitivity of our study to physician efficiency. Furthermore, since we did not directly measure time spent by physicians with patients, but rather used productivity as a proxy with the assumption that faster EPs interacted less with their patients. We also assumed that the effects of shift variability (both from a departmental flow and physician productivity perspective) leading to fluctuations in productivity would have been mitigated by the large number of surveys filled out per physician (mean $=29$ ) over the 37-month study period. Nonetheless, these limitations may have impacted our ability to detect a difference and may have introduced bias.

Thus, we acknowledge that in the ED, where medical complexity varies significantly from one patient interaction to the next, the number of patients seen per hour is a simplistic measure of productivity, less robust than the USA RVU model, which incorporates physician work, practice expense, and opportunity cost of specialty training. ${ }^{26,34-39}$ However, in Canada no standardised comprehensive measure of productivity exists. Until a more complete productivity tool is adopted in Canada, we feel that "patients seen per hour" is a reasonable metric.

Finally, though it is well documented that other variables such as wait times, crowding, and interactions with non-physician ED staff all influence patient satisfaction, ${ }^{5,10,12-15}$ we were unable to determine how 


\begin{tabular}{|c|c|c|c|c|c|}
\hline \multirow[b]{2}{*}{ Outcome variable } & \multicolumn{2}{|c|}{ Pre-determined variable } & \multirow{2}{*}{$\begin{array}{l}\text { Total } \\
\text { effect }\end{array}$} & \multirow{2}{*}{$\begin{array}{c}\text { Indirect effects } \\
\text { Via average productivity }\end{array}$} & \multirow{2}{*}{$\begin{array}{r}\text { - Direct } \\
\text { effect }\end{array}$} \\
\hline & Variable & Element & & & \\
\hline \multirow[t]{6}{*}{ Staff care and communication } & Admitted patients & Percentage of patients admitted & -0.013 & 0.001 & -0.014 \\
\hline & Patients' age & $\begin{array}{l}\text { Average age of physicians' } \\
\text { patients }\end{array}$ & -0.013 & 0.007 & -0.020 \\
\hline & Physician training & Base case: CCFP-EM & & & \\
\hline & program & FRCPC & -0.104 & 0.003 & -0.107 \\
\hline & Physician age & Age in 2012 & -0.025 & -0.002 & -0.023 \\
\hline & Physician productivity & Average productivity & -0.061 & & -0.061 \\
\hline \multirow[t]{6}{*}{ Pain management } & Admitted patients & Percentage of patients admitted & 0.050 & -0.001 & 0.051 \\
\hline & Patients' age & $\begin{array}{l}\text { Average age of physicians' } \\
\text { patients }\end{array}$ & 0.022 & -0.005 & 0.027 \\
\hline & Physician training & Base case: CCFP-EM & & & \\
\hline & program & FRCPC & -0.004 & -0.001 & -0.003 \\
\hline & Physician age & Age in 2012 & -0.158 & 0.001 & -0.159 \\
\hline & Physician productivity & Average productivity & 0.041 & & 0.041 \\
\hline \multirow[t]{6}{*}{ Discharge communication } & Admitted patients & Percentage of patients admitted & 0.165 & 0.001 & 0.164 \\
\hline & Patients' age & $\begin{array}{l}\text { Average age of physicians' } \\
\text { patients }\end{array}$ & -0.111 & 0.016 & -0.127 \\
\hline & Physician training & Base case: CCFP-EM & & & \\
\hline & program & FRCPC & -0.078 & 0.006 & -0.084 \\
\hline & Physician age & Age in 2012 & -0.005 & -0.004 & -0.001 \\
\hline & Physician productivity & Average productivity & -0.136 & & -0.136 \\
\hline \multirow{6}{*}{ Respect } & Admitted patients & Percentage of patients admitted & -0.033 & 0 & -0.033 \\
\hline & Patients' age & $\begin{array}{l}\text { Average age of physicians' } \\
\text { patients }\end{array}$ & 0.094 & 0.002 & 0.092 \\
\hline & Physician training & Base case: CCFP-EM & & & \\
\hline & program & FRCPC & 0.169 & 0.001 & 0.168 \\
\hline & Physician age & Age in 2012 & 0.015 & -0.001 & 0.016 \\
\hline & Physician productivity & Average productivity & -0.018 & & -0.018 \\
\hline \multirow[t]{6}{*}{ Medication communication } & Admitted patients & Percentage of patients admitted & $0.188^{*}$ & 0 & $0.188^{*}$ \\
\hline & Patients' age & $\begin{array}{l}\text { Average age of physicians' } \\
\text { patients }\end{array}$ & -0.149 & -0.002 & -0.147 \\
\hline & Physician training & Base case: CCFP-EM & & & \\
\hline & program & FRCPC & -0.023 & -0.001 & -0.022 \\
\hline & Physician age & Age in 2012 & -0.106 & 0.001 & -0.107 \\
\hline & Physician productivity & Average productivity & 0.023 & & 0.023 \\
\hline \multirow[t]{6}{*}{ Wait time and crowding } & Admitted patients & Percentage of patients admitted & $0.214^{*}$ & 0.001 & $0.213^{*}$ \\
\hline & Patients' age & $\begin{array}{l}\text { Average age of physicians' } \\
\text { patients }\end{array}$ & 0.062 & 0.009 & 0.053 \\
\hline & Physician training & Base case: CCFP-EM & & & \\
\hline & program & FRCPC & -0.093 & 0.003 & -0.096 \\
\hline & Physician age & Age in 2012 & -0.109 & -0.003 & -0.106 \\
\hline & Physician productivity & Average productivity & -0.076 & & -0.076 \\
\hline
\end{tabular}

variables such as learner involvement, illness acuity, and treatment outcome influenced our data. ${ }^{30,40}$ Such a study would require significantly greater resources to determine the influence of these multiple variables. We recommend that future studies account for these potential confounders. 


\section{CONCLUSION}

We found no association between EP productivity and the patient experience. Therefore, we failed to confirm our hypothesis that patient experience is inversely related to physician speed. Patient experience is influenced by many variables but data from our centers do not suggest that EP practice speed is a critical determinant of measurable differences in patient experience.

Competing Interests: None declared.

\section{SUPPLEMENTARY MATERIAL}

To view supplementary material for this article, please visit http://dx.doi.org/10.1017/cem.2016.385

\section{REFERENCES}

1. CAEP. Emergency Department Overcrowding. Available at: http://caep.ca/advocacy/romanow-commission/emergencydepartment-overcrowding (accessed October 30, 2012).

2. Canadian Institute for Health Information. Understanding emergency department wait times: who is using the emergency department and bow long are they waiting. Ottawa: Canadian Institute for Health Information; 2005.

3. Bullard MJ, Villa-Roel C, Bond K, et al. Tracking emergency department overcrowding in a tertiary care academic institution. Healthc Q 2009;12(3):99-106.

4. Preyde M, Crawford K, Mullins L. Patients' satisfaction and wait times at Guelph General Hospital Emergency Department before and after implementation of a process improvement project. CFEM 2012;14(3):157-68.

5. Yarris LM, Frakes B, Magaret N, et al. How accurately can emergency department providers estimate patient satisfaction? West $\mathcal{F}$ Emerg Med 2012;13(4):351-7.

6. Hoot NR, Aronsky D. Systematic review of emergency department crowding: causes, effects, and solutions. Ann Emerg Med 2008;52(2):126-36.

7. Blomqvist A, Busby C. How to pay family doctors: why pay per patient is better than fee for service. C.D. Howe Institute Commentary October 2012; 365:2-14. Available at: https:// www.cdhowe.org/sites/default/files/attachments/research_papers/ mixed/Commentary_365.pdf (accessed June 7, 2016).

8. Moffatt F, Timmons S, Coffey F. ED healthcare professionals and their notions of productivity. Emerg Med 7 2016; epub, doi: 10.1136/emermed-2015-205164.

9. Sun BC, Adams J, Orav EJ, et al. Determinants of patient satisfaction and willingness to return with emergency care. Ann Emerg Med 2000;35:426-34.

10. Hansagi H, Carlsson B, Brismar B. The urgency of care need and patient satisfaction at a hospital emergency department. Health Care Manage Rev 1992;17(2):71-5.
11. Yarnold PR, Michelson EA, Thompson DA, et al. Predicting patient satisfaction: a study of two emergency departments. 7 Behav Med 1998;21(6):545-63.

12. Boudreaux ED, O'Hea EL. Patient satisfaction in the Emergency Department: a review of the literature and implications for practice. 7 Emerg Med 2004;26(1):13-26.

13. Wartman SA, Morlock LL, Malitz FE, et al. Patient understanding and satisfaction as predictors of compliance. Med Care 1983;21(9):886-91.

14. McCarthy ML, Ding R, Zeger SL, et al. A randomized controlled trial of the effect of service delivery information on patient satisfaction in an emergency department fast track. 7 Emerg Med 2011;18(7):674-85.

15. Bhakta HC, Marco CA. Pain management: association with patient satisfaction among emergency department patients. 7 Emerg Med 2014;46(4):456-64.

16. Health Quality Council of Alberta. 2009-10 Urban \& Regional Emergency Department Patient Experience Technical Report. Calgary: Health Quality Council of Alberta; 2010.

17. Cydulka RK, Tamayo-Sarver J, Gage A, et al. Association of patient satisfaction with complaints and risk management among emergency physicians. 7 Emerg Med 2011;41(4): 405-11.

18. Cassidy-Smith TN, Baumann BM, Boudreaux ED. The disconfirmation paradigm: Throughput times and emergency department patient satisfaction. 7 Emerg Med 2007; 32(1):7-13.

19. Sun BC, Adams JG, Burstin HR. Validating a model of patient satisfaction with emergency care. Ann Emerg Med 2001;38(5):527-32.

20. Thompson DA, Yarnold PR, Williams DR, et al. Effects of actual waiting time, perceived waiting time, information delivery, and expressive quality on patient satisfaction in the emergency department. Ann Emerg Med 1996;28(6):657-65.

21. Bursch B, Beezy J, Shaw R. Emergency department satisfaction: what matters most? Ann Emerg Med 1993;22(3):586-91.

22. Pines JM, Iyer S, Disbot M, et al. The effect of emergency department crowding on patient satisfaction for admitted patients. Acad Emerg Med 2008;15(9):825-31.

23. Jenkinson C, Coulter A, Bruster S. The Picker Patient Experience Questionnaire: development and validation using data from in-patient surveys in five countries. Int 7 Qual Health Care 2002;14(5):353-8.

24. Bullen N, Reeves R, Richards N. Development and pilot testing of the NHS Acute Trust Outpatient Survey 2003; 2003. Available at: http://www.nhssurveys.org/Filestore/ documents/Emergency_dev_report.pdf.

25. Health Quality Council of Alberta. Emergency Department Patient Experience Survey. Calgary: Health Quality Council of Alberta; 2008. Available at: https://d10k7k7mywg42z. cloudfront.net/assets/5320b963f002ff30ec0002ca/HQCA_ED_ survey_technical_report_2008.pdf.

26. Moore KJ. A productivity primer. Fam Pract Manag 2002; 9(5):72-3.

27. Klem L. Path Analysis. In: Reading and Understanding Multivariate Statistics (eds. Grimm LG, Yarnold PR). Washington, DC: American Psychological Association; 1995,65 . 
28. Streiner DL. Finding our way: an introduction to path analysis. Can 7 Psychiatry 2005;50(2):115-22.

29. Cohen J, ed. Statistical Power Analysis for the Behavioral Sciences. 2nd ed. Hillsdale, NJ: Erlbaum; 1988.

30. Wood GC, Spahr R, Gerdes J, et al. Patient satisfaction and physician productivity: complementary or mutually exclusive? Am 7 Med Qual 2009;24(6):498-504.

31. Boudreaux ED, D'Autremont S, Wood K, et al. Predictors of emergency department patient satisfaction: stability over 17 months. Acad Emerg Med 2004;11(1):51-8.

32. Mercer MP, Hernandez-Boussard T, Mahadevan SV, et al. Physician identification and patient satisfaction in the emergency department: are they related? 7 Emerg Med 2014;46(5):711-8.

33. Castle NG, Brown J, Hepner KA, et al. Review of the literature on survey instruments used to collect data on hospital patients' perceptions of care. Health Serv Res 2005;40(6 Pt 2):1996-2017.

34. Indrayan A. Varieties of bias to guard against. In Basic Methods of Medical Research. 3rd ed. Delhi: AITBS Publishers; 2012, 99-106.
35. Hsiao WC, Braun P, Dunn D, et al. Results and policy implications of the resource-based relative-value study. $N$ Engl 7 Med 1988;319(13):881-8.

36. Silich BA, Yang JJ. Measuring emergency physicians' work: factoring in clinical hours, patients seen, and relative value units into 1 metric. West $\mathcal{F}$ Emerg Med 2012;13(2): 176-80.

37. Stecker EC, Schroeder SA. Adding value to relativevalue units. N Engl 7 Med 2013;369(23):2176-9.

38. Gauging Emergency Physician Productivity: Are RVUs the Answer? American College of Emergency Physicians; 2013. Available at: http://www.acep.org/Clinical-PracticeManagement/Gauging-Emergency-Physician-ProductivityAre-RVUs-the-Answer-/.

39. Jeanmonod R, DelCollo J, Jeanmonod D, et al. Comparison of resident and mid-level provider productivity and patient satisfaction in an emergency department fast track. Emerg Med 7 2013;30(1):e12.

40. Bhat R, Dubin J, Maloy K. Impact of learners on emergency medicine attending physician productivity. West 7 Emerg Med 2014;15(1):41-4. 